\title{
Structural Studies and Cytotoxicity of Trimethyl(ferrocenylmethyl)ammonium Iodide Encapsulated in $\beta$-Cyclodextrin
}

\author{
Sofia M. Bruno, ${ }^{\text {[a] }}$ José A. Fernandes, ${ }^{\text {[a] }}$ Joana Marques, ${ }^{\text {[a] }}$ Sara C. Neto, ${ }^{\text {[a] }}$ \\ Paulo J. Ribeiro-Claro, ${ }^{\text {[a] }}$ Martyn Pillinger, ${ }^{\text {[a] }}$ Filipe A. Almeida Paz, ${ }^{\text {aa] }}$ \\ Maria Paula M. Marques, ${ }^{[b]}$ Susana S. Braga, ${ }^{*[a]}$ and Isabel S. Gonçalves*[a]
}

\begin{abstract}
Keywords: Inclusion complexes / Host-guest systems / Cyclodextrins / Ferrocene derivatives / Structure elucidation / Density functional calculations / Cytotoxicity / Medicinal chemistry
\end{abstract}

Inclusion complexes that comprise $\beta$-cyclodextrin ( $\beta$-CD) and trimethyl(ferrocenylmethyl)ammonium iodide (1) have been prepared by codissolution of the host and guest in ethanol/ water, accompanied by either conventional heating at $40^{\circ} \mathrm{C}$ for $26 \mathrm{~h}$ (to give 2) or microwave-assisted heating for $30 \mathrm{~min}$ (to give 3 ). Solids were isolated and characterized by elemental and thermogravimetric analyses, powder X-ray diffraction (XRD), and IR, Raman, and ${ }^{13} \mathrm{C}\left\{{ }^{1} \mathrm{H}\right\}$ CP/MAS NMR spectroscopy. Powder XRD indicated the presence of microcrystalline inclusion compounds with supramolecular structures that comprise $\beta$-CD head-to-head dimers arranged into infinite channels. A small crop of single crystals of the inclusion compound 2 were obtained and analyzed by XRD. Despite diffraction being very poor above a resolution of around $1 \AA$, the data could be indexed to the space group $P 1$ (in agreement with powder XRD) and a reasonable structural model could be achieved when the asymmetric unit was composed of two directly located $\beta$-CD hosts, 1.4 iron atoms, and a small fraction of iodide anions. By using these data as a starting point, DFT calculations were carried out and led to a model of the crystal structure that comprised 2:1 (host/guest) and 2:2 adducts. The cytotoxic and antiproliferative activities of 1 and $\mathbf{2}$ were tested against the breast adenocarcinoma MDA-MB-231 and osteosarcoma MG-63 cell lines. Results indicate that both 1 and $\mathbf{2}$ are cytotoxic against the MDAMB-231 line but exhibit negligible activity on the MG-63 line.

\section{Introduction}

Ferrocene derivatives have attracted attention as potential antitumor drugs ever since the discovery of the antiproliferative action of ferrocenium complexes against Ehrlich ascites tumor (EAT). ${ }^{[1]}$ The cytotoxic behavior of ferrocenium derivatives is assumed to be based on their ability to generate active oxygen species that damage DNA. ${ }^{[2]}$ An appropriate choice of the substituents on the cyclopentadienyl $\left(\mathrm{Cp}^{\prime}\right)$ ring ensures biointeraction through in situ oxidation to ferrocenium, with excellent cancerostatic properties. ${ }^{[3]}$ Biomimicry is another successful design tool. Ferrocifen, conceived in the image of the natural drug tamoxifen, expanded the range of action to include not only estrogendependent but also estrogen-independent tumors. ${ }^{[4]} \mathrm{A}$ ferrocene-bearing analogue of nilutamide also showed excellent growth inhibition action on prostate cancer and an unexpected modified mechanism of action, independent of the androgen receptor binding pathway. ${ }^{[5]}$

[a] Department of Chemistry, CICECO, University of Aveiro, 3810-193 Aveiro, Portugal

Fax: +351-234-401470

E-mail:sbraga@ua.pt igoncalves@ua.pt

[b] Science and Technology Faculty, Molecular Physical Chemistry Research Group,

Department of Chemistry, University of Coimbra, PO Box 3126, 3001-401 Coimbra, Portugal
We have recently studied a series of disubstituted ferrocene complexes, with 2-( $N, N$-dimethylaminomethyl)ferrocene carboxamide and $N, N, N$-trimethyl- $N$-(2-carbamoylferrocenylmethyl)ammonium iodide being the most active, that have $\mathrm{IC}_{50}$ values in the range of $70-76 \mu \mathrm{M} .{ }^{[6]}$ Inclusion of the neutral complex into chemically modified $\beta$-cyclodextrins (CDs) such as the permethylated one (TRIMEB) and (2-hydroxy)propyl- $\beta$-cyclodextrin afforded higher activity with $\mathrm{IC}_{50}$ values of 25 and $20 \mu \mathrm{M}$, respectively. The parent compounds (native CDs) of chemically modified $\mathrm{CDs}$ are natural cyclic oligosaccharides formed from the bacterial degradation of starch, and typically comprise six $(\alpha-C D)$, seven $(\beta-C D)$, or eight $(\gamma-C D)$ glucose residues. Their good aqueous solubility combined with the hydrophobic cavities make them excellent solubilizers and molecular carriers for a wide range of organic and metalloorganic guests. ${ }^{[7]}$ For over two decades, CDs have been known to incorporate ferrocene ${ }^{[8]}$ and a vast number of its derivatives (Fcd). Apart from the encapsulation of the aforementioned monometallic Fcd antitumor agents, we have designed and prepared Fcd@CD inclusion compounds that contain heterobimetallic ${ }^{[9]}$ and oligo(ferrocenyldimethylsilane) guests, ${ }^{[10]}$ with potentially interesting electrochemical and catalytic properties.

In the present work, the cytotoxic potential of trialkyl(ferrocenylalkyl)ammonium salts has been further explored 
by using trimethyl(ferrocenylmethyl)ammonium iodide (1) as a model guest and native $\beta$-cyclodextrin $(\beta-C D)$ as a host (Figure 1); we have assessed the effect of molecular encapsulation on antiproliferative activity. The inclusion complex was prepared by codissolution of the two components, and the effect of using microwave-assisted heating (MAH) during this process was studied. The use of alternative, faster, cheaper and greener methods in the preparation of new compounds with potential activity strongly contributes to their marketing viability. Indeed, MAH has growing acceptance in the preparation of organic compounds by lowering reaction times, using cleaner solvents, and reducing the amount of byproducts. ${ }^{[1]}$ To date, the preparation of supramolecular cyclodextrin adducts by MAH remains largely unexplored.

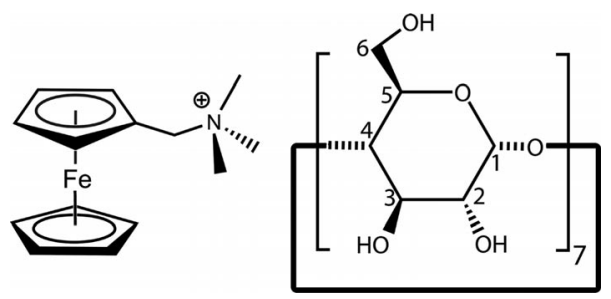

Figure 1. The trimethyl(ferrocenylmethyl)ammonium cation (left) and $\beta-C D$ (right).

\section{Results and Discussion}

\section{Synthesis and Characterization of the $\beta-C D$ Inclusion Compounds}

Inclusion complexation was carried out by combining a solution of trimethyl(ferrocenylmethyl)ammonium iodide (1) in a $25 \%$ ethanol/water mixture $(6 \mathrm{~mL})$ with a solution of $\beta$-CD in water at $40{ }^{\circ} \mathrm{C}$ (host/guest molar ratio of $1: 1$ ). The resulting solution was then stirred at either $40^{\circ} \mathrm{C}$ for $26 \mathrm{~h}$ (to give 2) or subjected to MAH for $30 \mathrm{~min}$ (to give 3). Yellow microcrystalline solids were obtained by concentrating the solutions and cooling them to $5{ }^{\circ} \mathrm{C}$.

The compositions of $\mathbf{2}$ and $\mathbf{3}$ were determined by performing microanalyses for $\mathrm{C}, \mathrm{H}$, and N; ICP-OES for Fe; and thermogravimetric analysis (TGA) for water content. Results indicate bulk host/guest molar ratios of 1.7:1 for 2 and 1.5:1 for 3 (please see the Exp. Section for details). TGA of 2 and 3 showed a weight loss of $11.2 \%$ from room temperature up to $125^{\circ} \mathrm{C}$ (Figure 2), which is in agreement with the calculated values (10.5 and $11.4 \%$, respectively) based on approximately 9-10 water molecules per CD molecule in $\mathbf{2}$ and $\mathbf{3}$. The onset of $\beta-C D$ decomposition occurs at $230{ }^{\circ} \mathrm{C}$ for both samples, a temperature lower than that of pure $\beta$-CD hydrate, which starts to decompose around $275-280^{\circ} \mathrm{C}$. Host decomposition at lower temperature is a common phenomenon in inclusion compounds with metallo-organic guests and has been associated with a strong, synergistic host-guest interaction. ${ }^{[6,12]}$ Another interesting feature in the TGA of $\mathbf{2}$ and $\mathbf{3}$ is the endothermal event that occurs around $240-250{ }^{\circ} \mathrm{C}$, which is strong enough to cause an inflexion in the thermal decomposition trace, due to the local absorption of heat that leads to a slight decrease of the temperature near the sensor, which is, in the equipment used for the data collection, placed a few millimeters from the sample crucible. The result is a dataset in which the temperature axis presents, after $245^{\circ} \mathrm{C}$, some points with decreasing temperature values (back to $243{ }^{\circ} \mathrm{C}$ before it starts to increase again, as normal). This phenomenon may be related to the decomposition of the guest, which, under the same synergistic effect mentioned for the host decomposition, undergoes a faster and almost linearly abrupt mass loss, thereby culminating in the endothermal event around $245^{\circ} \mathrm{C}$.

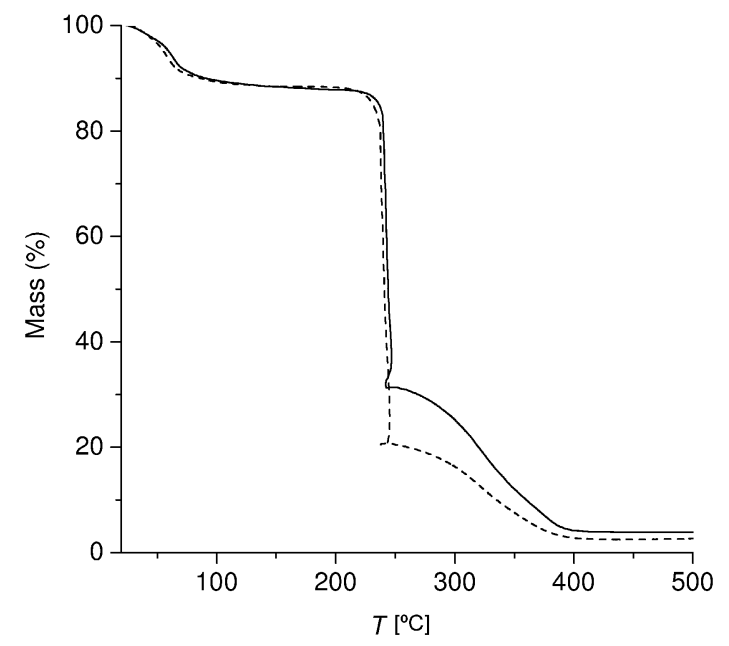

Figure 2. TGA curves of 2 (-) and 3 (-- $)$.

The IR and Raman spectra of $\mathbf{2}$ and $\mathbf{3}$ are dominated by the vibrational bands of the host. Nevertheless, a few bands due to the trimethyl(ferrocenylmethyl)ammonium ion can be discerned, and some of these are weakly shifted in relation to the corresponding bands for pure 1 , which may be a consequence of the molecular encapsulation (at the same time being consistent with a relatively weak host-guest interaction, as expected). For example, in the IR spectra of $\mathbf{2}$ and 3, the Fe-ring stretch appears at $477 \mathrm{~cm}^{-1}$, which represents a redshift of about $10 \mathrm{~cm}^{-1}$ relative to that for pure 1. ${ }^{[13]}$ In the Raman spectra of the inclusion compounds, a band assigned to a cyclopentadienyl ring stretching mode is present at $1448 \mathrm{~cm}^{-1}$ for 2 [cf. approximately $1426 \mathrm{~cm}^{-1}$ (shoulder) in the IR] and $1445 \mathrm{~cm}^{-1}$ for 3, relative to $1444 \mathrm{~cm}^{-1}$ for pure 1. Other guest bands for 2 and 3 are observed at $1247 \mathrm{~cm}^{-1}$ (blueshifted; at $1238 \mathrm{~cm}^{-1}$ for $\mathbf{1}$ ), and at 764,738 and $326 \mathrm{~cm}^{-1}$ (redshifted; at 768, 750, and $334 \mathrm{~cm}^{-1}$ for $\left.\mathbf{1}\right)$.

The ${ }^{13} \mathrm{C}\left\{{ }^{1} \mathrm{H}\right\}$ CP/MAS NMR spectra of $\mathbf{2}$ and $\mathbf{3}$ were collected and compared with those of the starting materials, compound 1 and $\beta-C D$, as depicted in Figure 3. The spectrum of $\beta$-CD hydrate exhibits multiple sharp resonances for each chemically distinct carbon atom $\left(\mathrm{C}^{1-6}\right)$, which has previously been attributed to small variations in the torsion angle that describes the conformations about the glycosidic linkages and the angle that describes the conformations of 
the $\mathrm{C}^{6}$ hydroxy groups. ${ }^{[14]}$ After inclusion complexation to give 2 and 3 , each of the four main groups of host resonances $\left(\mathrm{C}^{1}, \mathrm{C}^{4}, \mathrm{C}^{2,3,5}\right.$, and $\left.\mathrm{C}^{6}\right)$ span over a narrower chemical-shift range than pure $\beta$-CD. In fact, the signals for $\mathrm{C}^{1}$ and $\mathrm{C}^{2,3,5}$ appear as single broad peaks (with shoulders). These spectral features are closely related with the formation of $\beta$-CD dimers by hydrogen bonding that involves the $\mathrm{C}^{2}$ and $\mathrm{C}^{3}$ hydroxy groups located on the wider rim of the host. This packing geometry, described for $\mathbf{2}$ in the crystallographic section below, is associated with an overall symmetrization of the host macrocycle, evidenced by resonance reduction in the solid-state ${ }^{13} \mathrm{C}\left\{{ }^{1} \mathrm{H}\right\}$ NMR spectra. The spectra of $\mathbf{2}$ and $\mathbf{3}$ contain additional guest resonances at $\delta=69.3\left(\mathrm{CH}_{2} \mathrm{~N}\right), 52.5\left[\mathrm{~N}\left(\mathrm{CH}_{3}\right)_{3}\right]$, and around $71.5 \mathrm{ppm}$ (shoulder, $\mathrm{C}_{5} \mathrm{H}_{5}$ and $\mathrm{C}_{5} \mathrm{H}_{4} \mathrm{R}$ ), which are essentially unshifted relative to the corresponding signals exhibited by $\mathbf{1}$ in the solid-state NMR spectrum.

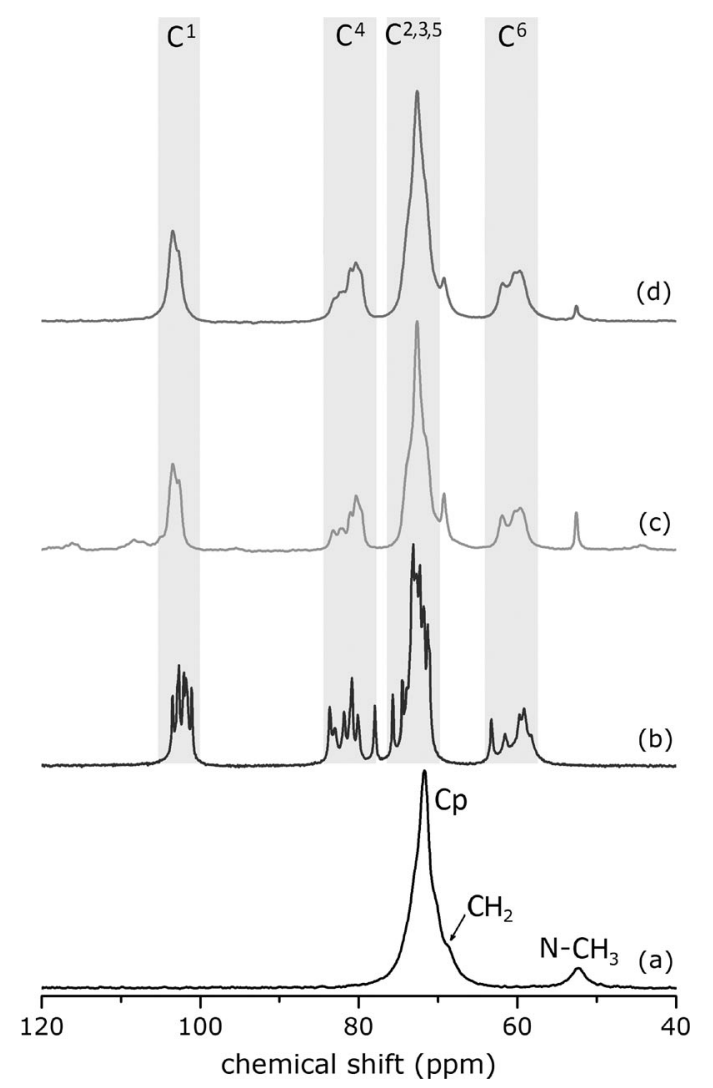

Figure $3 .{ }^{13} \mathrm{C}\left\{{ }^{1} \mathrm{H}\right\} \mathrm{CP} / \mathrm{MAS}$ NMR spectra of (a) the guest complex 1, (b) $\beta$-CD hydrate, and the inclusion compounds (c) 2, and (d) 3. Figure 1 shows the carbon atom numbering for the $\beta-C D$ host molecule.

The bulk powders that precipitated after cooling the mixed solutions of $\beta-C D$ and $\mathbf{1}$ were studied by powder XRD to investigate sample purity, homogeneity, and the formation of new phases that correspond to inclusion compounds. As depicted in Figure 4, both $\mathbf{2}$ and $\mathbf{3}$ are crystalline phases with no reflections associated with either pure 1 or $\beta-\mathrm{CD}$, thus confirming the absence of contamination from the starting materials. Hence, the bulk host/guest mo- lar ratios determined for 2 and 3 (1.7:1 and 1.5:1, respectively) are not due to the presence of either a 2:1 inclusion compound contaminated with pure $\mathbf{1}$ or a $1: 1$ inclusion compound contaminated with pure $\beta$-CD hydrate. Indeed, the diffraction traces for $\mathbf{2}$ and $\mathbf{3}$ are strongly correlated to a reference trace calculated (from single-crystal XRD coordinates) for inclusion compounds that belong to the channel $P 1$ series, one of the two isostructural series characterized by channel-type packing of $\beta$-CD head-to-head dimers; ${ }^{[15]}$ these series differ only in the space groups, which can be $C 2$ or $P 1$. Besides numerous inclusion compounds with organic guests, $\beta-\mathrm{CD}$ adducts with organometallics can also belong to these series, in particular diferrocenyldimethylsilane, ${ }^{[10 a]}$ a few half-sandwich molybdenum carbonyl complexes, ${ }^{[16]}$ and a family of mixed sandwich complexes. ${ }^{[17]}$

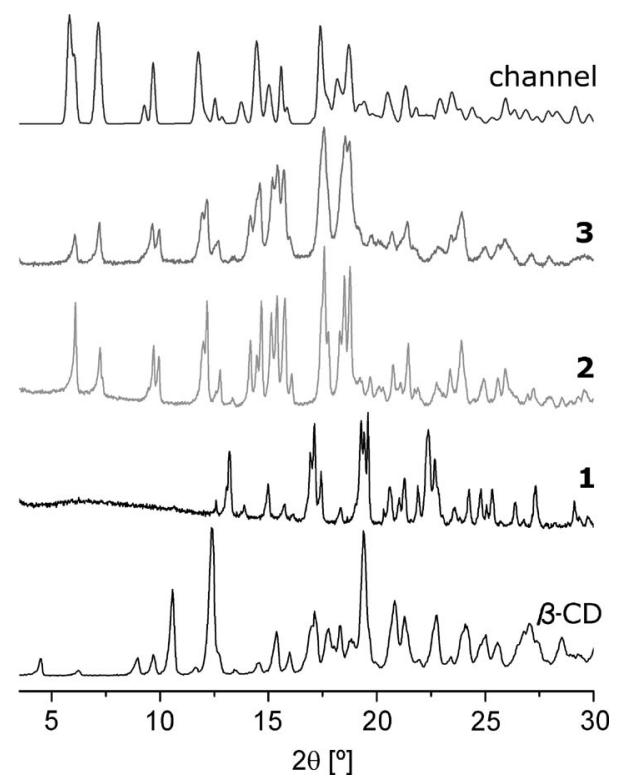

Figure 4. Powder XRD patterns of (from bottom to top) plain $\beta$ CD hydrate, the guest complex $\mathbf{1}$, the inclusion compounds $\mathbf{2}$ and $\mathbf{3}$, and a calculated model pattern for the isostructural series of $\beta$ $\mathrm{CD}$ inclusion compounds that belong to the space group $P 1$, which comprise infinite channels of head-to-head host dimers. ${ }^{[15]}$

Dimeric $\beta-\mathrm{CD}$ inclusion compounds crystallize, as established by Caira, ${ }^{[15]}$ in either the triclinic $P 1$ or the monoclinic $C 2$ space groups, with nearly indistinguishable diffractograms. To unequivocally assess the crystal symmetry of $\mathbf{2}$, attempts were made to isolate single crystals. As described in the Exp. Section, slow evaporation of the mixed solution of $\beta-C D$ and $\mathbf{1}$ (mother liquor) at low temperature gave a small crop of single crystals, which were indexed by using preliminary XRD analyses. All tested crystals were identified as belonging to the triclinic $P 1$ isostructural series. ${ }^{[15]}$ It is thus fair to infer that individual crystals are indeed representative of the whole microcrystalline sample. The crystallographically independent $\beta-C D$ molecules in the asymmetric unit are almost superimposable if one assumes the existence of an artificial $C_{2}$ axis running through the exact position where it would be for space group $C 2$ 
(Figure 5). However, crystal refinement was unstable and led to poor crystalline models, thus ruling out this latter space group.

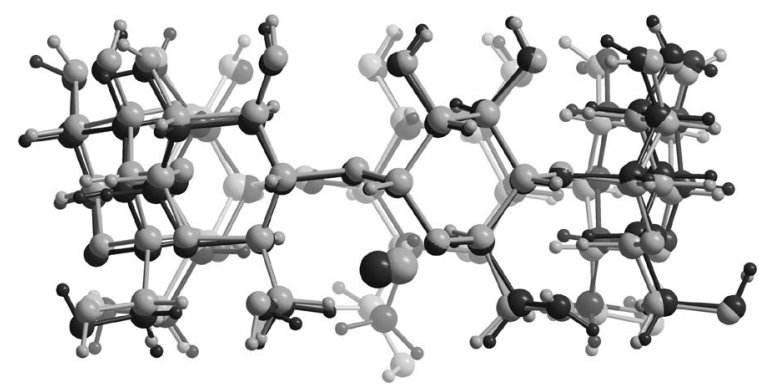

Figure 5. Superimposition of the two nonequivalent pairs of hostguest units from 2, performed by rotation about an artificial $C_{2}$ axis. Despite being nonequivalent, the structures overlay reasonably well.

In spite of the large number of single crystals isolated and tested from several distinct reaction batches, diffraction was systematically very poor above a resolution of around $1 \AA$, even for very long frame-exposure times. A reasonable structural model, supported by a stable overall refinement, could be achieved when the asymmetric unit was composed of two directly located (from difference Fourier maps) $\beta$ CD hosts, 1.4 iron atoms per unit cell, and a small fraction of iodide anions ( 0.65 per unit cell; 0.40 inside the $\beta$-CD cavity). Considerable structural disorder (both positional and thermal) attributed to the remaining chemical species (guests, counterions, and solvent molecules) led to a smeared-out electron density that prevented both their location or modeling (even when employing heavily constrained models). Nevertheless, the location of the host species and, therefore, the description of the crystal-packing motif clearly shows the typical channel packing of head-to-head dimers of $\beta$-CD molecules as described by Caira (head and tail rims separated by around 2.6 and $4.5 \AA$, respectively).

\section{DFT Calculations for Inclusion Compound 2}

Studies of the geometry of the inclusion compound $\mathbf{2}$ were performed using in silico methods. To significantly simplify the theoretical calculations, we used the aforementioned artificial $C_{2}$ rotation axis, in spite of it being absent in the crystalline structure. This choice circumvents the double simulation that would be necessary had we assumed the nonequivalence of the two cyclodextrin molecules in the unit cell.

The crystallographic studies reveal the presence of $1.4 \mathrm{Fe}$ and $0.4 \mathrm{I}^{-}$included in each $\beta$-CD dimer. This way, the overall crystal may be treated as a mixture of 1:1 adducts and hosts that only contain water molecules, excluding the iodide from the calculations due to its low occupation value. The initial step involved the simulation of such 1:1 compounds, which can have two possible geometries: $\mathrm{A}^{\mathrm{i}}$, with the trimethylammonium moiety directed towards the head of its host, and $\mathrm{B}^{\mathrm{i}}$, with this "tail" facing outwards through the narrower rim of $\beta-C D$. Partial optimization (keeping the $\beta$-CD hosts and iron atoms fixed and allowing the ligands to optimize freely) of these initial predefined structures afforded structures A and B, shown in Figure 6.
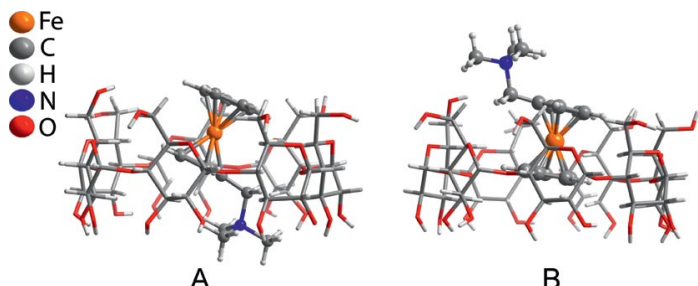

Figure 6. Schematic representation of two hypothetical arrangements of 1:1 $\beta$-CD inclusion compounds with guest 1 . Structures $\mathrm{A}$ and $\mathrm{B}$ were derived from the partial optimization of $\mathbf{1}$ inside the $\beta-C D$ cavity. Calculations were performed at the B3LYP/6-31G level, with fixed geometry of the hosts.

These arrangements were translated to the crystalline structure to certify their reliability. Although the fitting of structure A in the crystal packing produced a viable structure, in model B some of the contacts between the guest trimethylammonium moiety and the neighboring $\beta-\mathrm{CD}$ molecules were too short. This superposition compelled us to carry out a more complete simulation in which parts of the neighboring cyclodextrins were also present. The newly simulated structure, $\mathrm{B}^{*}$, has subtle differences that allow the accommodation of the trimethylammonium moiety in the interstices between the two neighboring cyclodextrins. The energies, calculated for the models in the presence of a $\beta$ $\mathrm{CD}$ neighbor, are $15 \mathrm{~kJ} \mathrm{~mol}^{-1}$ lower for $\mathrm{A}$ than for $\mathrm{B}^{*}$; thus, a distinction between them cannot be based on such a small energy difference. The reliability of the presented structures depends, among other factors, on the existence or otherwise of short contacts, namely, $\mathrm{H} \cdots \mathrm{H}$ contacts. The departing structures A and $\mathrm{B}^{*}$ exhibit some short distance contacts. Structure $\mathrm{B}^{*}$ has four short $\mathrm{H} \cdot \cdot \mathrm{H}$ contacts in the range 1.764-1.977 $\AA$ between the $\mathrm{N}\left(\mathrm{CH}_{3}\right)_{3}$ moiety and the neighboring $\beta$-CD molecules (two to its own host, and two to the other $\beta$-CD molecule). The shortest contact distance in structure $\mathrm{A}$ is at $1.999 \AA$, which is considerably larger than those of $\mathrm{B}^{*}$.

The combination of geometries A and $\mathrm{B}^{*}$ with empty cyclodextrins gives the structure of the two possible $2: 1$ adducts $C(A+\beta-C D)$ and $D\left(B^{*}+\beta-C D\right)$ present in 2 (Figure 7).

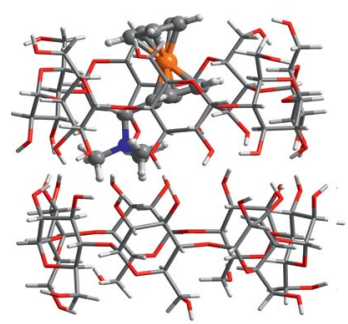

C
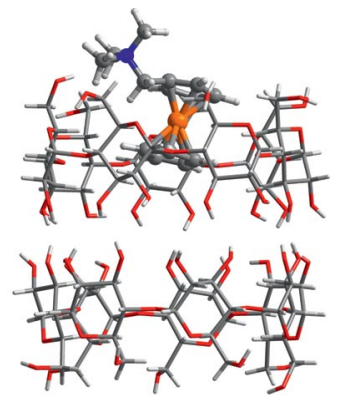

$\mathrm{D}$
Figure 7. Schematic representation of the structures C and D for 2:1 adducts determined from a combination of XRD data (all $\beta$ $\mathrm{CD}$ molecules and the iodide anion) and theoretical modeling (ferrocene molecules). 
The formation of 2:2 adducts by the geometric combination of pairs of structures $A$ and $B^{*}$ produced three different types of adducts, namely, $\mathrm{A}_{2}, \mathrm{AB}$, and $\mathrm{B}_{2}$. This combination required no change in the short contact distances between guests and hosts, except for $\mathrm{A}_{2}^{*}$, which had very short contacts between the two guests and thus required a further optimization step to afford $\mathrm{H} \cdots \mathrm{H}$ contacts of at least 1.925 and $1.997 \AA$ (the shortest found). However, the two parts of structure $B_{2}$, which are related by imposed symmetry, do not interact evenly with the crystalline scaffold and a very short contact distance of $1.178 \AA$ is found. This is most likely the result of the purely geometric construction of this dimer assuming an artificial $C_{2}$ axis, and thus the short distance should not be considered an impeding factor. Indeed, a distance between hydrogen atoms smaller than the sum of van der Waals radii is usual in geometry optimizations, and even distances shorter than $2 \AA$ (like the present ones) are not completely artificial. ${ }^{[18]}$ The final structures presented here (Figure 8) are not fully optimized, with many of the short distances arising from the rigidity of the $\beta-\mathrm{CD}$ molecule. A full optimization could enlarge such distances, but being very time-consuming and computer-expensive, it falls beyond the scope of the present study.
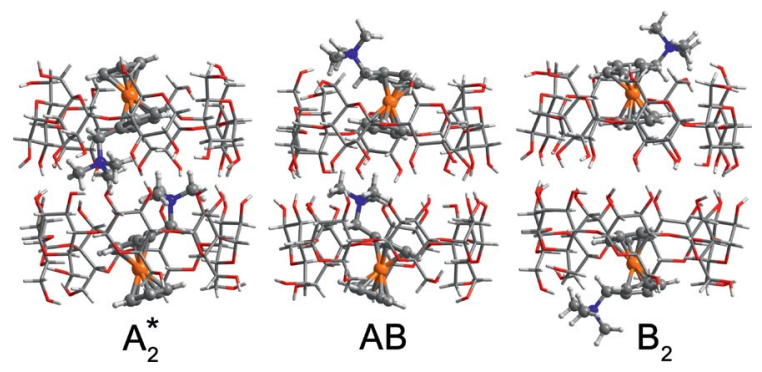

Figure 8. Schematic representation of the structures $A_{2}^{*}, A B$, and $\mathrm{B}_{2}$ for 2:2 adducts determined from a combination of XRD data ( $\beta$-CD molecules) and theoretical modeling (guest molecules).

With regards to the $\mathrm{I}^{-}$anion, and in spite of its low occupation factor established from crystallography, important atomic superimpositions are observed when it is placed in models $\mathrm{C}, \mathrm{A}_{2}^{*}, \mathrm{~B}_{2}$, and $\mathrm{AB}$. In model $\mathrm{D}$, the distance between the $\mathrm{I}^{-}$and $\mathrm{Cp}(4.982 \AA)$ is the optimum value for such distance, thus implying that the anion may interact with the Cp ligand. Therefore, only structure $\mathrm{D}$ is compatible with the presence of the iodide, and this structure is present approximately in a 0.4 fraction. The possible structures for the 2:2 adducts are independent of the mass balance, and therefore only the energy difference can be a factor of differentiation between them. Thus, the lowest energy corresponds to model $\mathrm{A}_{2}^{*}$, which is $61 \mathrm{~kJ} \mathrm{~mol}^{-1}$ lower than $\mathrm{AB}$ and $125 \mathrm{~kJ} \mathrm{~mol}^{-1}$ lower than $\mathrm{B}_{2}$.

A mass balance to the approximate iron content and the total content shows that the fractions of empty $\beta-\mathrm{CD}$ dimers or structure $\mathrm{C}$ are considerably reduced or even null. In short, in so far as the calculations are correct, we can infer that the crystal structure of $\mathbf{2}$ comprises structures D and $\mathrm{A}_{2}^{*}$ (in a molar ratio close to $3: 2$ to give the bulk host/ guest ratio of 1.43:1), with small amounts of the other possible structures.

The overall host/guest molar ratio of 1.43 in the model of the crystal structure of $\mathbf{2}$ is slightly lower than the values determined experimentally for the bulk microcrystalline solids 2 and $\mathbf{3}$ (1.7 and 1.5, respectively). Nevertheless, we may conclude that a similar model holds for these bulk inclusion compounds, except that they contain a slightly higher proportion of 2:1 head-to-head dimers (structure D).

\section{Cytotoxic and Antiproliferative Studies of 2}

The antiproliferative effects of complex 1 , its $\beta-\mathrm{CD}$ adduct 2 , and native $\beta-C D$ were evaluated towards the MG63 osteosarcoma and MDA-MB-231 breast adenocarci-
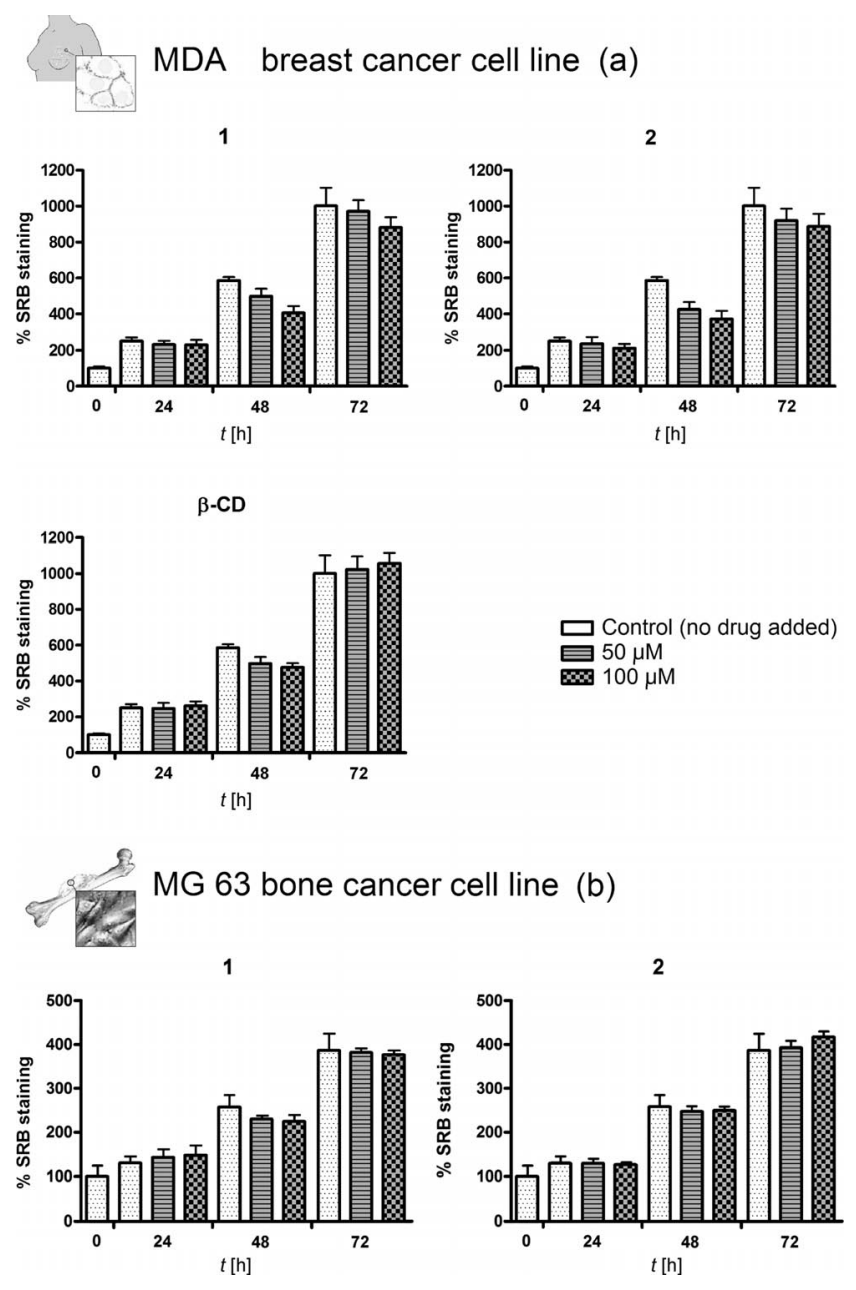

Figure 9. Time- and dose-dependent antiproliferative profiles for compounds 1, 2, and native $\beta-C D$ against (a) MDA-MB-231 and (b) MG-63 cell lines. Cells were plated at a density of

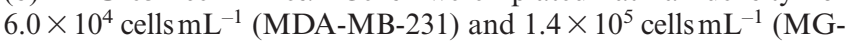
63 ) on 24 -well plates, and incubated with the drugs for 24,48 , and $72 \mathrm{~h}$. After $72 \mathrm{~h}$, cell density was evaluated using the sulforhodamine B (SRB) colorimetric assay. Results are expressed as a percentage of the control $(100 \%)$ and represent the average \pm standard deviation from the experiments carried out in triplicate. ${ }^{*} p<0.05$ by Tukey's post hoc test, after one-way analysis of variance (ANOVA). 
noma (hormone-independent) human cell lines. The inhibition at a $72 \mathrm{~h}$ incubation period clearly evidences that compounds $\mathbf{1}$ and $\mathbf{2}$ are more active against the MDA-MB-231 cell line than towards the MG-63 cells (Figure 9).

Regarding the breast carcinoma line, the two compounds already display antiproliferative properties after $24 \mathrm{~h}$ of incubation. For 48 and $72 \mathrm{~h}$ the growth-inhibiting activity of both compounds is consistent with the increase in drug concentration; it is more significant after an incubation period of $48 \mathrm{~h}$ and for the inclusion compound $\mathbf{2}$. A slight reversible effect is observed at $72 \mathrm{~h}$ for both compounds. The $\beta$ $\mathrm{CD}$ host alone was also tested on this cell line, with results showing, as expected, a lack of significant cytotoxic activity. On the other hand, inclusion of 1 into $\beta$-CD results in an enhancement of its growth-inhibitory profile, in particular for the concentration of $50 \mu \mathrm{M}$, which affords a growth inhibition very close to that observed for the highest concentration $(100 \mu \mathrm{M})$. This increase in antitumor activity is consistent with the advantages of using cyclodextrins as hosts, which act as protective carriers and solubilizing agents and allow the drug dosage to be reduced by roughly one half. Such action is highly beneficial and improves the antineoplastic potential.

With reference to the MG-63 cell line, a significant antiproliferative effect was not observed for compounds $\mathbf{1}$ and 2 , even at a dosage of $100 \mu \mathrm{M}$, the highest concentration tested, and an incubation time of $72 \mathrm{~h}$. This cell line was chosen due to current research interests of our group, which aim for the development of new metal complexes with anticancer properties towards osteosarcoma, a highly resistant cancer for which there is a limited range of effective chemotherapeutic agents available. However, the present results clearly indicate that both $\mathbf{1}$ and $\mathbf{2}$ are unable to overcome this resistance problem associated with osteosarcoma. Plain $\beta$-CD was tested against this cell line in our previous work and has displayed no intrinsic antiproliferative effect. ${ }^{[14 \mathrm{e}]}$

\section{Conclusion}

Inclusion complexes that comprise $\beta-\mathrm{CD}$ and trimethyl(ferrocenylmethyl)ammonium iodide (1) were prepared by codissolution of the host and guest in ethanol/water, accompanied by either conventional heating at $40{ }^{\circ} \mathrm{C}$ for $26 \mathrm{~h}$ (to give 2) or microwave-assisted heating for $30 \mathrm{~min}$ (to give 3). Solid-state characterization of $\mathbf{2}$ and $\mathbf{3}$ provided details on their structure and geometry. A combination of crystallography and theoretical calculations applied to compound 2 showed that $\beta-C D$ molecules form dimers stacked into infinite channels, which accommodate the guest cations inside, the iodide counterion being disordered over intra-dimeric and inter-dimeric positions. For compound 3, no suitable single crystals were obtained, and diffraction studies were limited to the bulk powders. Nonetheless, the results are compatible with the formation of a channel-packed inclusion compound.

The pure guest $\mathbf{1}$ and the inclusion compound $\mathbf{2}$ were tested for their cytotoxic and antiproliferative activity on two human cancer cell lines, breast cancer MDA-MB-231 and osteosarcoma MG-63. The tested drugs showed cytotoxicity against the MDA-MB-231 line, more accentuated after $48 \mathrm{~h}$ of incubation and with a slight decrease (cell recovery) after $72 \mathrm{~h}$ of incubation. However, growth inhibition of the MG-63 cells was not achieved with these compounds at the concentrations tested (up to $100 \mu \mathrm{M}$ ), thus ruling them out as candidates for osteosarcoma treatment.

\section{Experimental Section}

General: $\beta$-CD hydrate was kindly donated by Roquette (France) and trimethyl(ferrocenylmethyl)ammonium iodide (1) was purchased from Alfa Aesar. Microanalyses for $\mathrm{CHN}$ were performed at the Department of Chemistry, University of Aveiro (by M. Marques), and Fe was determined by ICP-OES at the Central Laboratory for Analysis, University of Aveiro (by L. Carvalho). Powder X-ray diffraction (XRD) data of the bulk compounds were collected at ambient temperature with an $\mathrm{X}^{\prime}$ Pert MPD Philips diffractometer $\left(\mathrm{Cu}-K_{\alpha 1,2} \mathrm{X}\right.$-radiation, $\lambda_{1}=1.540598 \AA$ and $\lambda_{2}=$ $1.544426 \AA$ ), equipped with an $\mathrm{X}^{\prime}$ Celerator detector and a flatplate sample holder in a Bragg-Brentano parafocusing optics configuration $(40 \mathrm{kV}, 50 \mathrm{~mA})$. Intensity data were collected by the stepcounting method (step $0.02^{\circ}$ ), in continuous mode, in the approximately $4.0 \leq 2 \theta \leq 50.0^{\circ}$ range. Thermogravimetric analysis (TGA) was carried out with a Shimadzu TGA-50 system at a heating rate of $5^{\circ} \mathrm{Cmin}^{-1}$ under air. FTIR spectra were recorded with a Unican Mattson Mod 7000 FTIR spectrophotometer. FT Raman spectra were recorded at room temperature in the $70-4000 \mathrm{~cm}^{-1}$ range with an RFS-100 Bruker FT spectrometer with $2 \mathrm{~cm}^{-1}$ resolution, using a Nd:YAG laser (Coherent Compass-1064/500) with an excitation wavelength of $1064 \mathrm{~nm} .{ }^{13} \mathrm{C}\left\{{ }^{1} \mathrm{H}\right\}$ CP/MAS NMR spectra were recorded at room temperature and $125.72 \mathrm{MHz}$ with a Bruker Avance 500 spectrometer and an optimized $\pi / 2$ pulse for ${ }^{1} \mathrm{H}$ of $4.5 \mu \mathrm{s}$, $2 \mathrm{~ms}$ contact time, a spinning rate of $9 \mathrm{kHz}$, and $12 \mathrm{~s}$ recycle delays. Chemical shifts are quoted in parts per million from tetramethylsilane.

MAH was carried out with a Discover S-class (CEM corporation, USA) microwave oven, at $2.45 \mathrm{GHz}$ and $20 \mathrm{psi}$ air, while stirring and simultaneous cooling with compressed air to prevent bulk overheating. A dynamic control operation mode was used with an MW power input of $250 \mathrm{~W}$, temperature control set point of $60^{\circ} \mathrm{C}$, hold time of $30 \mathrm{~min}$, high stirring speed without prestirring, and power max (cooling during microwave application for higher energy) off. The solution obtained was then allowed to slowly cool to room temperature.

Preparation of the Inclusion Compounds: A solution of $1(0.099 \mathrm{~g}$, $0.259 \mathrm{mmol})$ in a $25 \%$ ethanol/water mixture $(6 \mathrm{~mL})$ was added to a solution of $\beta-C D(0.340 \mathrm{~g}, 0.259 \mathrm{mmol})$ in water $(10 \mathrm{~mL})$ at $40{ }^{\circ} \mathrm{C}$. The resulting mixture was then stirred at either $40^{\circ} \mathrm{C}$ for $26 \mathrm{~h}$ (to give 2 ) or subjected to MAH for $30 \mathrm{~min}$ (to give 3 ). In both cases, yellow solutions were obtained, which were concentrated and cooled to $5^{\circ} \mathrm{C}$, thereby resulting in the formation of yellow solid products. The mother liquors were removed by decantation and the solids were washed with a cold aqueous solution that contained $25 \%$ ethanol, and finally air-dried (isolated yields $=0.16 \mathrm{~g}$ for 2 and $0.26 \mathrm{~g}$ for $\mathbf{3}$ ). For $\mathbf{2}$, the mother liquor was slowly evaporated at $4{ }^{\circ} \mathrm{C}$ over a period of several weeks, thereby resulting in a small crop of single crystals, which were subjected to XRD analyses (see below).

Inclusion Complexation Performed with Conventional Heating at $40{ }^{\circ} \mathrm{C}$ (2): $1.7\left(\mathrm{C}_{42} \mathrm{H}_{70} \mathrm{O}_{35}\right) \cdot\left(\mathrm{C}_{14} \mathrm{H}_{20} \mathrm{NFeI}\right) \cdot 15 \mathrm{H}_{2} \mathrm{O}$ (2584.6): calcd. $\mathrm{C}$ 
39.68, H 6.59, N 0.54, Fe 2.16\%; found C 39.99, H 6.41, N 0.48, $\mathrm{Fe} 2.22 \%$. TGA up to $125{ }^{\circ} \mathrm{C}$ revealed a sample weight loss of $11.2 \%$ (calcd. for the loss of $15 \mathrm{H}_{2} \mathrm{O}, 10.5 \%$ ). FTIR $(\mathrm{KBr}): \tilde{v}=$ 3352 (vs), 2924 (m), 2903 (sh), 1632 (m), 1426 (sh), 1413 (m), 1383 (w), 1368 (w), 1334 (m), 1302 (m), 1246 (m), 1204 (m), 1158 (s), 1101 (s), 1079 (s), 1054 (vs), 1027 (vs), 1002 (s), 944 (m), 938 (m), $863(\mathrm{~m}), 758(\mathrm{~m}), 702(\mathrm{~m}), 607(\mathrm{sh}), 587(\mathrm{sh}), 576(\mathrm{~m}), 529(\mathrm{~m}), 477$ (w), $445(\mathrm{w}), 414(\mathrm{w}), 360(\mathrm{~m}) \mathrm{cm}^{-1}$. FT Raman: $\tilde{v}=3391(\mathrm{w}), 3275$ (w), 3109 (s), 3076 (m), 2946 (vs), 2900 (vs), 1460 (s), 1448 (sh), 1411 (s), 1382 (s), 1328 (s), 1264 (m), 1247 (s), 1140 (m), 1106 (vs), 1088 (m), 1043 (s), 999 (w), $974(\mathrm{w}), 948$ (m), $926(\mathrm{~m}), 869$ (s), 764 (w), $738(\mathrm{~m}), 708(\mathrm{w}), 648(\mathrm{w}), 619(\mathrm{w}), 599(\mathrm{~m}), 576(\mathrm{~m}), 536(\mathrm{w})$, 501 (m), 481 (vs), 450 (m), 413 (m), 396 (m), 357 (m), 325 (s), 312 (m), $221(\mathrm{~m}) \mathrm{cm}^{-1} \cdot{ }^{13} \mathrm{C}\left\{{ }^{1} \mathrm{H}\right\} \mathrm{CP} / \mathrm{MAS}$ NMR: $\delta=103.4,102.6(\beta-$ $\mathrm{CD}, \mathrm{C}^{1}$; see Figure 1 for carbon atom numbering), 83.3, 82.2, 81.0, $80.4\left(\beta-\mathrm{CD}, \mathrm{C}^{4}\right), 72.6\left(\beta-\mathrm{CD}, \mathrm{C}^{2,3,5}\right), 71.5$ (sh, guest, $\left.\mathrm{Cp}+\mathrm{Cp}^{\prime}\right)$, 69.3 (guest, $\mathrm{CH}_{2} \mathrm{~N}$ ), 62.1, 59.7, $\left(\beta-\mathrm{CD}, \mathrm{C}^{6}\right), 52.6$ [guest, $\mathrm{N}\left(\mathrm{CH}_{3}\right)_{3}$ ] ppm.

Inclusion Complexation Performed with MAH (3): $1.5\left(\mathrm{C}_{42} \mathrm{H}_{70} \mathrm{O}_{35}\right)$. $\left(\mathrm{C}_{14} \mathrm{H}_{20} \mathrm{NFeI}\right) \cdot 15 \mathrm{H}_{2} \mathrm{O}(2357.8)$ : calcd. C 39.22, H 6.63, N 0.59, Fe $2.37 \%$; found $\mathrm{C} 38.95, \mathrm{H} 6.75, \mathrm{~N} 0.60, \mathrm{Fe} 2.40 \%$. TGA up to $125^{\circ} \mathrm{C}$ revealed a sample weight loss of $11.2 \%$ (calcd. for the loss of $15 \mathrm{H}_{2} \mathrm{O}, 11.4 \%$ ). FTIR (KBr): $\tilde{v}=3356$ (vs), $2923(\mathrm{~m}), 2905$ (sh), $1636(\mathrm{~m}), 1435$ (sh), $1416(\mathrm{~m}), 1383$ (w), 1369 (w), 1333 (m), 1302 (w), 1247 (m), 1204 (m), 1158 (s), 1101 (s), 1079 (s), 1053 (vs), 1027 (vs), 1002 (s), 944 (m), 937 (m), 859 (m), 757 (m), 702 (m), 602 (sh), 587 (sh), 577 (m), 528 (m), 475 (w), 443 (w), 413 (w), 357 (m) $\mathrm{cm}^{-1}$. FT Raman: $\tilde{v}=3372(\mathrm{~m}), 3269(\mathrm{~m}), 3107(\mathrm{~s}), 3081(\mathrm{~m})$, 2946 (vs), 2902 (vs), 1459 (s), 1445 (sh), 1413 (s), 1380 (s), 1332 (s), 1264 (sh), 1248 (s), 1139 (m), 1106 (vs), 1087 (s), 1043 (s), 1002 (w), 975 (w), 948 (s), 923 (s), 870 (s), 847 (sh), 764 (m), 738 (s), 706 (m), $649(\mathrm{w}), 617(\mathrm{w}), 596(\mathrm{~m}), 575(\mathrm{w}), 533(\mathrm{w}), 500(\mathrm{~m}), 480(\mathrm{vs})$, 448 (m), 415 (m), 397 (m), 354 (m), 326 (s), 313 (s), $222(\mathrm{~s}) \mathrm{cm}^{-1}$. ${ }^{13} \mathrm{C}\left\{{ }^{1} \mathrm{H}\right\}$ CP/MAS NMR: $\delta=103.5,102.8\left(\beta-\mathrm{CD}, \mathrm{C}^{1}\right), 83.0,82.0$, 81.1, $80.4\left(\beta-\mathrm{CD}, \mathrm{C}^{4}\right), 72.6\left(\beta-\mathrm{CD}, \mathrm{C}^{2,3,5}\right), 71.5$ (sh, guest, $\mathrm{Cp}+$ $\mathrm{Cp}^{\prime}$ ), 69.2 (guest, $\mathrm{CH}_{2} \mathrm{~N}$ ), 61.8, 60.3, $59.6\left(\beta-\mathrm{CD}, \mathrm{C}^{6}\right), 52.5$ [guest, $\left.\mathrm{N}\left(\mathrm{CH}_{3}\right)_{3}\right]$ ppm.

Single-Crystal X-ray Diffraction: A manually selected single crystal of $\mathbf{2}$ was mounted on a Hampton Research CryoLoop ${ }^{[19]}$ with the help of highly viscous FOMBLIN Y perfluoropolyether vacuum oil (LVAC 140/13; purchased from Sigma-Aldrich) and a Stemi 2000 stereomicroscope equipped with Carl Zeiss lenses. Data were collected at 120(2) K with a Bruker X8 Kappa APEX II CCD areadetector diffractometer (Mo- $K_{\alpha}$ graphite-monochromated radiation, $\lambda=0.7107300 \AA$ with relative uncertainty of $0.0000089 \AA$ ) controlled by the APEX2 software package, ${ }^{[20]}$ and equipped with an Oxford Cryosystems Series 700 cryostream monitored remotely using Cryopad. ${ }^{[21]}$ Images were processed using SAINT+, ${ }^{[22]}$ and data were corrected for absorption by the multiscan semiempirical method implemented in SADABS. ${ }^{[23]}$ The structure was solved using the direct methods algorithm implemented in SHELXS$97,{ }^{[24 a, 24 b]}$ which allowed the immediate location of the majority of the atoms that composed the $\beta$-cyclodextrin moieties. All remaining non-hydrogen atoms from the host moieties, and those of the located guest species, were located from difference Fourier maps calculated from successive full-matrix least-squares refinement cycles on $F^{2}$ using SHELXL-97.[24a,24c]

The selected single crystal (the best tested from several distinct batches) was a very small brown prism (maximum dimension of around $0.06 \mathrm{~mm}$; see below), which diffracted very weakly at high angle, even for very long frame exposures, hence the low data completeness (of about $91.7 \%$ ) up to a resolution of approximately
$0.83 \AA$. In addition, the average values of $I / \sigma$ for a resolution above around $1.00 \AA$ are smaller than 1.0 , clearly showing the weak diffraction of the material and fully explaining the high $R 1$ and $\mathrm{w} R 2$ values calculated for $\mathbf{2}$. Nevertheless, as mentioned above, all nonhydrogen atoms that belong to the two crystallographically independent $\beta$-CD molecules could be directly located from difference Fourier maps and refined without the use of distance restraints. The general location of two crystallographically independent trimethyl(ferrocenylmethyl)ammonium cations could also be derived from the integrated data set. These moieties were, however, severely affected by thermal disorder and had to be refined with fixed partial occupancies of 80 and $60 \%$, while also using a battery of distance restraints to ensure chemically reasonable geometries for the cyclopentadienyl rings bound to the central iron atoms. Because of the smeared-out electron density that surrounds these included guest species, a sensible location and refinement of the substituent pendant groups of the cyclopentadienyl moieties could not be achieved. In a similar fashion, the crystallographic location of two charge-balancing iodide anions could be derived from difference Fourier maps, but these moieties were ultimately included in the final structural model with fixed rates of occupancy of only 40 and $25 \%$. The remaining negative charge required to fully compensate the cationic excess of the modeled trimethyl(ferrocenylmethyl)ammonium complexes could not be attributed to other chemical moieties due to the aforementioned smeared-out electron density. Nevertheless, due to the chemical analysis results, this charge should also be attributed to (highly disordered) iodide anions.

Poor data quality prevented a sensible overall refinement, which could only be achieved by assuming isotropic displacement behavior for all non-hydrogen atoms. Carbon and oxygen atoms associated with the $\beta-\mathrm{CD}$ molecules were included in the final structural model by assuming a common (and refineable) isotropic displacement parameter (one for each type of atom). The same strategy was employed for those carbon atoms that belong to the ferrocene derivatives.

Hydrogen atoms bound to carbon and oxygen from the two crystallographically independent $\beta$-CD hosts were placed at their idealized positions using appropriate HFIX instructions in SHELXL (13 for the tertiary carbon atoms, 23 for the $-\mathrm{CH}_{2}-$ moieties, and 147 for the terminal $-\mathrm{OH}$ moieties) and included in subsequent refinement cycles in riding-motion approximation with isotropic thermal displacement parameters $\left(U_{\text {iso }}\right)$ fixed at 1.2 (for the two former families of hydrogen atoms) or 1.5 (only for the $-\mathrm{OH}$ moieties) times $U_{\text {eq }}$ of the attached atom. No hydrogen atoms have been included in the two modeled crystallographically independent trimethyl(ferrocenylmethyl)ammonium cations.

The structural model described in the previous paragraphs still contains a large number of inner voids: total volume of about $812 \AA^{3}$ as estimated by PLATON, ${ }^{[25]}$ and distributed among three major cavities within the unit cell. These voids most likely contain highly disordered solvent molecules. A number of attempts to locate and model these solvent molecules proved to be unproductive because of the smeared-out electron density. The original data set was then treated using the SQUEEZE subroutines ${ }^{[26]}$ implemented in PLATON to remove the contribution of these highly disordered molecules. It was ultimately estimated that the aforementioned cavities would contain a total of around 345 electrons. The calculated solvent-free reflection list was used for further structural refinements, ultimately converging to the solvent-free structure reported in this manuscript and with the reliability factors summarized below.

Structural drawings have been created using Diamond. ${ }^{[27]}$ CCDC817404 (2) contains the supplementary crystallographic data for 
this paper. These data can be obtained free of charge from The Cambridge Crystallographic Data Centre via www.ccdc.cam.ac.uk/ data_request/cif.

Crystal (SQUEEZE) Data for 2: $\mathrm{C}_{98} \mathrm{H}_{140} \mathrm{Fe}_{1.40} \mathrm{I}_{0.65} \mathrm{O}_{70}, M_{\mathrm{r}}=$ 2598.78, triclinic, space group $P 1, T=120(2) \mathrm{K}, Z=1, a=$ 15.388(3) $\mathrm{A}, b=15.489(3) \AA, c=17.810(4) \AA, a=113.374(6)^{\circ}, \beta$ $=99.149(6)^{\circ}, \gamma=102.662(5)^{\circ}, V=3655.6(13) \AA^{3}, \mu\left(\right.$ Mo- $\left.K_{\alpha}\right)=$ $0.367 \mathrm{~mm}^{-1}, D_{\text {calcd. }}=1.180 \mathrm{~g} \mathrm{~cm}^{-3}$, brown blocks with crystal size of $0.06 \times 0.03 \times 0.02 \mathrm{~mm}^{3}$. Of a total of 28303 reflections collected, 19945 were independent $\left(R_{\text {int }}=0.0720\right)$. Final $R 1=0.1322$ $[I>2 \sigma(I)]$ and $w R 2=0.3187$ (all data). Data completeness to $\theta=$ $25.35^{\circ}, 91.7 \%$.

Determination of Guest-Inclusion Geometry in the Crystals: Ab initio calculations were performed using the $\mathrm{G} 03 \mathrm{w}$ package ${ }^{[28]}$ on the multiprocessor cluster "Flamingo" that belongs to CICECO, University of Aveiro. The B3LYP method at the 6-31G level was used. The molecular geometry of the $\beta$-CD host was that of the crystal structure determined from single-crystal XRD (see the previous subsection for additional experimental details).

The models for $\mathbf{2}$ were simulated by iterative geometry fitting of the guest included in the fixed geometry (as determined from single-crystal XRD) of the host. The location of the iron atom was reasonably determined in the crystal, so its position was fixed in the calculations. By contrast, the $\mathrm{Cp}^{\prime}\left(\eta^{5}-\mathrm{C}_{5} \mathrm{H}_{5}, \eta^{5}-\mathrm{C}_{5} \mathrm{H}_{4} \mathrm{R}\right)$ carbon atoms from the crystal structure were only used for assembling the first premise of the calculations, but were not fixed. Two different $1: 1$ adducts (model $\mathrm{A}$ and $\mathrm{B}$ ) were calculated concerning different locations for the ammonium moiety of the guest. The validation of the calculated models was performed by transposing them to crystal packing, in which some superimposition in model B was found. A new structure, $\mathrm{B}^{*}$, derived from $\mathrm{B}$ was calculated with the presence of part of the neighboring molecules in the model. The final structures of the 2:1 and 2:2 adducts were constructed by geometric manipulation of the structures $\mathrm{A}, \mathrm{B}^{*}$, and empty $\beta$-cyclodextrins. The 2:2 adduct $\mathrm{A}_{2}$ had some short distances between the guests, which led to the calculation of a new structure $A_{2}^{*}$ derived from $A_{2}$.

Cytotoxic and Antiproliferative Studies. Preparation of Solutions for Biological Assays: All compounds studied were water soluble. Solutions were prepared at concentrations that ranged from $5.0 \times 10^{-5}$ to $1.0 \times 10^{-4} \mathrm{M}$ in phosphate buffered saline (PBS) solution $\left(140.0 \times 10^{-3} \mathrm{M} \mathrm{NaCl}, 2.7 \times 10^{-3} \mathrm{M} \mathrm{KCl}, 1.5 \times 10^{-3} \mathrm{M} \mathrm{KH}_{2} \mathrm{PO}_{4}\right.$, $8.1 \times 10^{-3} \mathrm{M} \mathrm{Na}_{2} \mathrm{HPO}_{4}$ in Milli-Q water, $\mathrm{pH}$ 7.4) and sterilized by filtration. Sulforhodamine B (SRB) was used as a $0.5 \%(w / v)$ solution in $1 \%(\mathrm{v} / \mathrm{v})$ acetic acid.

Cell Culture: Stock cultures of MG-63 and MDA-MB-231 cells were maintained at $37^{\circ} \mathrm{C}$ in a humidified atmosphere under $5 \%$ $\mathrm{CO}_{2}$. MG-63 cells (grown in monolayers) were kept in Eagle's minimum essential medium (MEM), supplemented with 10\% heat-inactivated fetal bovine serum, $1 \mathrm{~mm}$ sodium pyruvate, and nonessential amino acids and antibiotics (100 units of penicillin and $100 \mathrm{mg}$ of streptomycin). MDA-MB-231 cells (grown in monolayers) were kept in RPMI-1640 culture medium, supplemented with sodium hydrogencarbonate $\left(2 \mathrm{~g} \mathrm{~L}^{-1}\right), 10 \%$ fetal bovine serum, $1 \mathrm{~mm}$ sodium pyruvate, and nonessential amino acids and antibiotics (100 units of penicillin and $100 \mathrm{mg}$ of streptomycin). The two cell lines were subcultured twice a week and harvested upon addition of trypsin/ EDTA (0.05\% trypsin/EDTA solution).

Toxicity and Cell Growth Inhibition Evaluation: Cytotoxicity and cell density evaluation following drug exposure (drug concentrations of 50 and $100 \mu \mathrm{m} ; 24,48$, and $72 \mathrm{~h}$ of incubation time) were assessed using the SRB colorimetric assay. This assay determines the cell density and the drug-induced cytotoxicity based on the measurement of the cellular protein content. The protein dye SRB binds to basic amino acid residues of trichloroacetic acid-fixed cells; it was quantitatively extracted from cells and solubilized by a weak base solution for optical density measurement at $540 \mathrm{~nm}$. ${ }^{[29]}$ MG-63 cells were plated at a density of $1.4 \times 10^{5}$ cells $\mathrm{mL}^{-1}$ and MDA-MB-231 cells at $6.0 \times 10^{4}$ cells mL $\mathrm{mL}^{-1}$ on 24 -well plates. Drug solutions were added to the medium $24 \mathrm{~h}$ after seeding, and the cultures were incubated at $37^{\circ} \mathrm{C}$. After $72 \mathrm{~h}$, cells were fixed with ice-cold $1 \%$ acetic acid in methanol for $2 \mathrm{~h}$. SRB was then added to each well and allowed to stain for $1 \mathrm{~h}$ at $37^{\circ} \mathrm{C}$. The excess amount of SRB solution was removed by washing the plates with $1 \%$ acetic acid the plates were then air-dried. The bound SRB was solubilized in a $10 \mathrm{~mm}$ Tris base solution $(\mathrm{pH}=10)$. Measurements were carried out in a microplate reader at a working wavelength of $540 \mathrm{~nm}$

Statistical Analysis of Growth Inhibition Results: All experiments were performed in triplicate. Results are expressed as a percentage of the control $(100 \%)$ and represent the mean values \pm standard deviation (the corresponding error bars are displayed in the graphical plots). Statistical analysis was performed by analysis of variance (ANOVA). Tukey's post hoc test was used for statistical comparison between the experimental data. Values of $p$ less than 0.05 were considered significant.

Supporting Information (see footnote on the first page of this article): Crystallographic information file (excluding structure factors) for 2 .

\section{Acknowledgments}

We are grateful to the Fundação para a Ciência e a Tecnologia (FCT), Orçamento de Estado (OE), and Fundo Europeu de Desenvolvimento Regional (FEDER) through the programme COMPETE (Programa Operacional Factores de Competitividade), for their general financial support, and for specific funding towards the purchase of the single-crystal diffractometer. The FCT and the European Social Fund, through the Programma Operacional Potencial Humano (POPH), are acknowledged for a $\mathrm{PhD}$ grant to J. M. (SFRH/BD/44791/2008), and for postdoc grants to S. M. B. (SFRH/BPD/46473/2008) and J. A. F. (SFRH/BPD/63736/2009).

[1] a) P. Köpf-Maier, H. Köpf, E. W. Neuse, J. Cancer Res. Clin. Oncol. 1984, 108, 336-340; b) C. Ornelas, New J. Chem., DOI: $10.1039 / \mathrm{c} 1 \mathrm{nj} 20172 \mathrm{~g}$.

[2] a) D. Osella, M. Ferrali, P. Zanello, F. Laschi, M. Fontani, C. Nervi, G. Cavigiolio, Inorg. Chim. Acta 2000, 306, 42-48; b) G. Tabbi, C. Cassino, G. Cavigiolio, D. Colangelo, A. Ghiglia, I. Viano, D. Osella, J. Med. Chem. 2002, 45, 5786-5796.

[3] G. Caldwell, M. G. Meirim, E. W. Neuse, C. E. J. Rensburg, Appl. Organomet. Chem. 1998, 12, 793-799.

[4] a) S. Top, A. Vessières, C. Cabestaing, I. Laios, G. Leclercq, C. Provot, G. Jaouen, J. Organomet. Chem. 2001, 637, 500-506; b) S. Top, A. Vessières, G. Leclercq, J. Quivy, J. Tang, J. Vaissermann, M. Huche, G. Jaouen, Chem. Eur. J. 2003, 9, 5223-5236.

[5] O. Payen, S. Top, A. Vessières, E. Brulé, M. A. Plamont, M. J. McGlinchey, H. Müller-Bunz, G. Jaouen, J. Med. Chem. 2008, 51, 1791-1799.

[6] Ž. Petrovski, M. R. P. N. de Matos, S. S. Braga, C. C. L. Pereira, M. L. Matos, I. S. Gonçalves, M. Pillinger, P. M. Alves, C. C. Romão, J. Organomet. Chem. 2008, 693, 675-684.

[7] F. Hapiot, S. Tilloy, E. Monflier, Chem. Rev. 2006, 106, 767781

[8] A. Harada, S. Takahashi, J. Chem. Soc., Chem. Commun. 1984, 645-646. 
[9] a) L. Cunha-Silva, I. S. Gonçalves, M. Pillinger, W. M. Xue, J. Rocha, J. J. C. Teixeira-Dias, F. E. Kühn, J. Organomet. Chem. 2002, 656, 281-287; b) Ž. Petrovski, S. S. Braga, S. S. Rodrigues, C. C. L. Pereira, I. S. Gonçalves, M. Pillinger, C. Freire, C. C. Romão, New J. Chem. 2005, 29, 347-354; c) Ž. Petrovski, S. S. Braga, A. M. Santos, S. S. Rodrigues, I. S. Gonçalves, M. Pillinger, F. E. Kühn, C. C. Romão, Inorg. Chim. Acta 2005, 358, 981-988.

[10] a) J. A. Fernandes, S. Lima, S. S. Braga, P. Ribeiro-Claro, J. E. Rodríguez-Borges, C. Teixeira, M. Pillinger, J. J. C. TeixeiraDias, I. S. Gonçalves, J. Organomet. Chem. 2005, 690, 48014808; b) J. A. Fernandes, S. Lima, S. S. Braga, M. Pillinger, J. E. Rodríguez-Borges, P. Ribeiro-Claro, J. J. C. Teixeira-Dias, I. S. Gonçalves, Eur. J. Inorg. Chem. 2005, 4729-4734; c) J. A. Fernandes, S. Lima, S. S. Braga, M. Pillinger, P. Ribeiro-Claro, J. E. Rodríguez-Borges, J. J. C. Teixeira-Dias, I. S. Gonçalves, Organometallics 2005, 24, 5673-5677.

[11] V. Polshettiwar, R. S. Varma, Chem. Soc. Rev. 2008, 37, 15461557.

[12] a) S. S. Braga, F. A. A. Paz, M. Pillinger, J. D. Seixas, C. C. Romão, I. S. Gonçalves, Eur. J. Inorg. Chem. 2006, 1662-1669; b) C. C. L. Pereira, S. S. Braga, F. A. A. Paz, M. Pillinger, J. Klinowski, I. S. Gonçalves, Eur. J. Inorg. Chem. 2006, 42784288; c) C. C. L. Pereira, M. Nolasco, S. S. Braga, F. A. A. Paz, P. Ribeiro-Claro, M. Pillinger, I. S. Gonçalves, Organometallics 2007, 26, 4220-4228.

[13] K. Nakamoto, Infrared Spectra of Inorganic and Coordination Compounds [Russian translation], 1966, Mir, Moscow.

[14] a) R. P. Veregin, C. A. Fyfe, R. H. Marchessault, M. G. Taylor, Carbohydr. Res. 1987, 160, 41-56; b) M. J. Gidley, S. M. Bociek, J. Am. Chem. Soc. 1988, 110, 3820-3829; c) S. J. Heyes, N. J. Clayden, C. M. Dobson, Carbohydr. Res. 1992, 233, 1-14; d) J. Marques, L. Anjo, M. P. M. Marques, T. M. Santos, F. A. A. Paz, S. S. Braga, J. Organomet. Chem. 2008, 693, 30213028; e) J. Marques, T. M. Santos, M. P. M. Marques, S. S. Braga, Dalton Trans. 2009, 9812-9819.

[15] M. R. Caira, Rev. Roum. Chim. 2001, 46, 371-386.

[16] a) S. S. Braga, I. S. Gonçalves, A. D. Lopes, M. Pillinger, J. Rocha, C. C. Romão, J. J. C. Teixeira-Dias, J. Chem. Soc., Dalton Trans. 2000, 2964-2968; b) S. Lima, I. S. Gonçalves, P. Ribeiro-Claro, M. Pillinger, A. D. Lopes, P. Ferreira, J. J. C. Teixeira-Dias, J. Rocha, C. C. Romão, Organometallics 2001, 20 , 2191-2197.

[17] B. Klingert, G. Rihs, J. Chem. Soc., Dalton Trans. 1991, 2749 2760.

[18] R. Casadesus, M. Moreno, A. Gonzalez-Lafont, J. M. Lluch, M. P. Repasky, J. Comput. Chem. 2004, 25, 99-105.
[19] T. Kottke, D. Stalke, J. Appl. Crystallogr. 1993, 26, 615-619.

[20] APEX2 Data Collection Software, Version 2.1-RC13, 2006, Bruker AXS, Delft, The Netherlands.

[21] Cryopad, Remote monitoring and control, version 1.451, 2006, Oxford Cryosystems, Oxford, United Kingdom.

[22] SAINT+, Data Integration Engine, version 7.23a, 1997-2005, Bruker AXS, Madison, Wisconsin, USA.

[23] G. M. Sheldrick, SADABS, version 2.01, 1998, Bruker/Siemens Area Detector Absorption Correction Program, Bruker AXS, Madison, Wisconsin, USA.

[24] a) G. M. Sheldrick, Acta Crystallogr., Sect. A: Found. Crystallogr. 2008, 64, 112-122; b) G. M. Sheldrick, SHELXS-97, Program for Crystal Structure Solution, University of Göttingen, 1997; c) G. M. Sheldrick, SHELXL-97, Program for Crystal Structure Refinement, University of Göttingen, 1997.

[25] a) A. L. Spek, Acta Crystallogr., Sect. A: Found. Crystallogr. 1990, 46, C34; b) A. L. Spek, J. Appl. Crystallogr. 2003, 36, 7 13.

[26] P. van der Sluis, A. L. Spek, Acta Crystallogr., Sect. A: Found. Crystallogr. 1990, 46, 194-201.

[27] K. Brandenburg, DIAMOND, version 3.2f, 1997-2010, Crystal Impact GbR, Bonn, Germany.

[28] M. J. Frisch, G. W. Trucks, H. B. Schlegel, G. E. Scuseria, M. A. Rob, J. R. Cheeseman, J. A. Montgomery Jr, T. Vreven, K. N. Kudin, J. C. Burant, J. M. Millam, S. S. Iyengar, J. Tomasi, V. Barone, B. Mennucci, M. Cossi, G. Scalmani, N. Rega, G. A. Petersson, H. Nakatsuji, M. Hada, M. Ehara, K. Toyota, R. Fukuda, J. Hasegawa, M. Ishida, T. Nakajima, Y. Honda, O. Kitao, H. Nakai, M. Klene, X. Li, J. E. Knox, H. P. Hratchian, J. B. Cross, V. Bakken, C. Adamo, J. Jaramillo, R. Gomperts, R. E. Stratmann, O. Yazyev, A. J. Austin, R. Cammi, C. Pomelli, J. W. Ochterski, P. Y. Ayala, K. Morokuma, G. A. Voth, P. Salvador, J. J. Dannenberg, V. G. Zakrzewski, S. Dapprich, A. D. Daniels, M. C. Strain, O. Farkas, D. K. Malick, A. D. Rabuck, K. Raghavachari, J. B. Foresman, J. V. Ortiz, Q. Cui, A. G. Baboul, S. Clifford, J. Cioslowski, B. B. Stefanov, G. Liu, A. Liashenko, P. Piskorz, I. Komaromi, R. L. Martin, D. J. Fox, T. Keith, M. A. Al-Laham, C. Y. Peng, A. Nanayakkara, M. Challacombe, P. M. W. Gill, B. Johnson, W. Chen, M. W. Wong, C. Gonzalez, J. A. Pople, Gaussian 03, rev. D.02, Gaussian, Inc., Wallingford, CT, 2003.

[29] P. Skehan, R. Storeng, D. Scudiero, A. Monks, J. McMahon, D. Vistica, J. T. Warren, H. Bokesch, S. Kenney, M. R. Boyd, J. Natl. Cancer Inst. 1990, 82, 1107-1112.

Received: June 28, 2011

Published Online: September 15, 2011 